\title{
obituary
}

\section{Sir Graham Sutton}

SiR Graham Sutton, former DirectorGeneral of the Meteorological Office, who died on 26 May 1977 at the age of 74, achieved eminence early in his career by fundamental contributions to the theory of atmospheric turbulence and diffusion.

His work in this field began in the late 1920s, when atmospheric boundarylayer theory was at a primitive stage. It had, however, become evident, from early observations of diffusion and from pioneering theoretical studies by G. I. Taylor and L. F. Richardson, that the diffusion of a plume of smoke could not be explained on the basis of a constant eddy diffusivity analogous to, but very much larger than, the molecular diffusivity of kinetic theory. The starting point of Sutton's theory of turbulent transfer was the combination of Taylor's famous theorem, for the kinetics of passive particles carried in a turbulent fluid, with the classical Prandtl mixing-length theory. This led to an explicit height-dependent form of the eddy diffusivity. It also led to the result that the spread of a plume of gas or fine particles issuing from a point in a wind was proportional to distance raised to a power between $\frac{1}{2}$ and 1 , the precise magnitude of this exponent and of the proportionality constant being determined by the form of the increase of wind with height above ground.

The consequences of this work have been wide-ranging and long-lasting. It provided the basis for the first formulae representing the effect of meteorological conditions on the concentrationfield downwind of a source of gas or particles, and Sutton's point-source formulae, at first in restricted use in chemical warfare studies, became widely known immediately after the 1939-45 war in the context of industrial air pollution. It also was a stimulus for continuing and far-reaching boundary-layer studies, notably of the wind profile, the aerodynamic drag of the earth's surface and the factors determining evaporation from water surfaces and transpiration from vegetation.

Oliver Graham Sutton was born in Cwmcarn, Monmouthshire, in 1903. He took his degrees in mathematics at Aberystwyth and Oxford and his first appointment was to a lectureship at Aberystwyth. Two years later, in 1928, he was persuaded by the late Sir David

\section{Sorry, for copyright reasons some images on this page may not be available online}

Brunt to join the Meteorological Office and shortly afterwards he was seconded to the War Office establishment at Porton, where the aforementioned work was carried out

In 1942 , with his potential for scientific administration already strongly evident, he was required to leave his meteorological team for wider wartime responsibilities as Superintendent of Research at Porton, and he was drawn into further fields of administration in posts as Superintendent of the Tank Armament Research Station (1943-45) and Chief Superintendent of the Radio Research and Development Establishment (1945-47).

In 1947 he returned to individual scientific work in the position of Bashforth Professor of Mathematical Physics at the Royal Military College of Science, Shrivenham, though here also wider responsibilities were to be placed on him, as Soientific Adviser to the Army Council (1951) and Dean of the Royal Military College (1952-53). $\mathrm{His}$ individual scientific achievements were recognised in his election as a Fellow of the Royal Society in 1949

During this phase of his career he was able to turn to more general writing on the fundamental science of boundary-layer meteorology, an ambition on which he had made a start while at Porton. His first published effort was Atmospheric Turbulence in the Methuen Monograph series (1949) and this was followed by his wellknown major work Micrometeorology
(1953), in which he covered the most important topics in the physics of the surface air layers. Although much had already been written on the qualitative aspects of those topics, Micrometeorology was the first connected account of the relevant principles and crucial observations in a full mathematical-physical setting. His capacity for exact mathematical analysis and lucid exposition of complex physical interpretations came out here to the full, and he was to make good use of the latter gift over more than two decades of writing for less specialised readers, as for example in his Science of Flight (1950) and The Weather (1974).

In $1953 \mathrm{Dr}$ Sutton accepted an invitation to become Director-General of the Meteorological Office, and for the next twelve years devoted his mature powers of leadership, scientific judgement and administrative skill to the formidable task of guiding its developing activities. His period of office saw the emergence of a fully-developed research division with the scope and reputation of a leading institute of meteorology. Technical resources were greatly expanded and included the installation of high-speed computing facilities. The services which meteorological science could usefully offer were extended far beyond those originally designed for weather forecasting and aviation. At the same time the hitherto scattered main branches of the Office were brought together in the present unified headquarters at Bracknell.

Sir Graham (he was knighted in 1955) planned to retire from professional activities in 1965 , but he was then persuaded to be first chairman of the Natural Environment Research Council. Here again his outstanding abilities as an administrator and his qualities of leadership were turned to an urgent and important task, that of ensuring the rapid and successful development of the new organisation for promoting the various sciences of the natural environment.

The many recognitions and awards received by Sir Graham included the Symons Memorial Gold Medal of the Royal Meteorological Society (1959), the International Meteorological Organization Prize (1968) and the Frank A. Chambers Award of the United States Air Pollution Control Association (1968). There were also countless demands on his time for work on com- 
mittees and in other organisations, and to many spells of service as chairman he invariably brought a balanced judgement, a diplomatic touch and a quiet sense of humour. While DirectorGeneral of the Meteorological Office he took a prominent part in the activities of the World Meteorological Organisation, especially as a member of its Executive Committee. $\mathrm{He}$ was President of the Royal Meteorological Society 1953-55. He also found time for the duties of a Justice of the Peace and for those of a member of the Council of the University College of Wales, Aberystwyth, of which he was Vice-President in his last few years.

F. Pasquill

\section{A. D. Walsh}

Professor A. Donald Walsh FRS died in Dundee, after a long illness, on 23 April 1977 in his sixty-first year. $\mathrm{He}$ was educated at Loughborough Grammar School and Corpus Christi College, Cambridge, where he was a Mawson Scholar. In 1938 he started research in vacuum ultra-violet spectroscopy under the direction of Professor W. C. Price and continued as an ICI Research Fellow until 1949, when he accepted a lectureship at Leeds University. In 1953 he was promoted to a Readership, and two years later was invited to take the Baxter Chair of Chemistry at Queen's College, Dundee, which was then part of the University of St. Andrews. In 1967, when Queen's College became the University of Dundee, Professor Walsh was appointed Dean of the Science Faculty. He was elected to the Royal Society of Edinburgh in 1959 and to the Royal Society in 1964.

Donald Walsh will always be remembered for his enthusiasm. Whether he was lecturing to a first-year class, discussing his latest research, or watching the flight of a bird while driving erratically along a country road, he radiated a fascinating and infectious enthusiasm for his subject.

It was this enthusiasm which marked his rise to the heights of his profession. The investigation of the electronic structure of small molecules and the nature of valence and chemical bonding were, for him, an absorbing study throughout his career. The topic suited his enquiring mind ideally, for he loved to put his ideas to the test and spent very many happy days fitting together his theories and his experimental spectra.

During the war, when it became necessary for research to have more practical application, Donald Walsh became involved in problems of gaseous combustion, such as the suppression of the exhaust flames which revealed the presence of our aeroplanes in the sky at night. After the war, he became more interested in the mechanism of gaseous combustion reactions, and in particular with the mechanism of anti-knocks in petrol engines. In this he was associated with Riccardo Ltd and later with Octel Ltd who still employ a number of his former students. Those privileged to hear him present his research papers in the 1950 s and 1960s will clearly recall the rival theories on anti-knock action put forward by Professors R. G. W. Norrish and A. D. Walsh, the debates being enlivened by the completely different personalities of these two eminent scientists. Donald Walsh was fond of simple experiments to demonstrate his ideas. One remembers the hydrogen peroxide which usually hit the ceiling in a demonstration that peroxides are rapidly decomposed by particulate lead oxide (an important part of his theory of the anti-knock action of lead alkyls.)

In Dundee his gentlemanly charm and hospitality quickly gained for him the loyalty of a department which rapidly grew under his direction and enthusiasm. His research students enjoyed many happy Saturday afternoons helping him construct his large garden, and they appreciated the generous quantities of Elin Walsh's magnificent teas which contrasted so markedly with student fare.

When Dundee gained independent status as a university in 1967, Donald Walsh was the obvious choice for Dean of the Faculty of Science-a Faculty which might have disappeared earlier but for his efforts. Extra duties did not deter him, and he habitually arrived in the Department at 6 a.m. after an overnight journey from Londonhe was still there at 7 p.m.

$\mathrm{He}$ bore his long fight with Parkinson's disease with typical fortitude as he was gradually forced to retire from chemistry and from the department to which he had devoted so much of his time and energy.

$$
\begin{aligned}
& \text { D. E. Hoare } \\
& \text { P. A. Warsop }
\end{aligned}
$$

\section{R. D. Brauer}

Richard Dagobert Brauer, who was one of the leading pure mathematicians of this century, died on 17 April 1977 at Belmont, Massachusetts. Born in Berlin in 1901, he studied at the university there under the distinguished algebraist Issai Schur. He taught at Königsberg until the political oppression in Germany forced him to leave in 1933. He held temporary posts at the University of Kentucky and the Institute for Advanced Study in Princeton. In 1935 he went to the University of Toronto, where he stayed until
1948; he then returned to the United States, and held chairs at the Universities of Michigan (1948-1952) and Harvard (1952-1971).

Brauer's work on the representation theory of groups has been a major influence in the development of algebra during the past half-century. Some of his earlier papers were concerned with the representations of semisimple continuous groups--Hermann Weyl's fundamental work on this subject appeared at about the time (1925-1926) when Brauer was presenting his doctoral thesis. Brauer's methods were more algebraic, and in some ways simpler than Weyl's. In fact Brauer worked as assistant to Weyl in Princeton in the year 1934-1935, and they wrote there a joint paper on spinors, which is the classical exposition of the mathematical background to Dirac's theory of the spinning electron.

From 1935 onwards, Brauer was increasingly concerned with the representation theory of finite groups. He developed a beautiful and deep theory of modular characters, which gave a completely new insight into the study of group characters. Group characters had been introduced in 1896 by Frobenius, and had already given, in the first decade of this century, some remarkable results on the structure of finite groups. It was Brauer who, thirty years later, resumed this work, and by the end of the 1950 s had laid the foundation of a method for attacking the very difficult problem of the classification of finite simple groups. His pioneering work was one of the starting points of a great advance in this problem. Brauer's active involvement in this research continued right up to the end of his life.

During his long career Richard Brauer received many academic honours and held some of the highest positions in his profession. But he retained a very gentle and unassuming manner, and a concern for the problems and interests of other mathematicians. His modesty about his own great achievements was proverbial-a mathematical conversation with him would usually become a conversation about the other person's work. A first impression of unworldliness was deceptive; he used his time very efficiently, and achieved a great deal in an unhurried manner. He became a kind of elder statesman among American algebraists, and his advice was sought and valued for its wisdom and humanity.

$\mathrm{He}$ is survived by his wife Ilse (née Karger) whom he married in 1925; also by his brother Alfred, and his two sons George and Fred, who are all mathematicians.

J. A. Green 